\title{
Therapeutic peptides
}

\author{
"The paradigm of drug discovery is now being changed by the new tendency of pharmaceutical companies \\ to directly develop a prodrug or a drug-delivery system."
}

The pharmaceutical industry is perhaps one of the most intriguing sectors of industry. First and foremost, it is devoted to the most vital need of mankind; namely, health. Furthermore, it ranks first for total $\mathrm{R} \& \mathrm{D}$ investment, it is one of the few sectors still growing in the current economic climate and five pharmaceutical companies occupy prominent positions in the world's top ten companies in terms of total R\&D investment (Roche first, Pfizer second, Merck US fifth, Novartis eighth and Johnson \& Johnson tenth) [1]. However, this sector is launching fewer products into the market every year. In the last 3 years (2009-2011) the US FDA has approved the release of only 76 new therapeutics, 58 new molecular entities and 18 new biologics [2-4]. Although the number of biologics is relatively stable (six every year), when products are analyzed by chemical species, the trend reveals that 'small molecules' are losing the prevalence they have enjoyed in recent years.

Figure I shows that for the period 2009-2011, only 34 small molecules were accepted by the FDA, which represents $45 \%$ of the total, while 18 'proteins' (including proteins, monoclonal antibodies and enzymes), which account for $24 \%$ of the total, were introduced into the market. The encouraging news for peptide scientists is that eight peptides ( $11 \%$ of the total) were accepted by the agency in this period of time. If one takes into account that far fewer academic and industrial laboratories are devoted to peptide drug synthesis than to small molecules, it can be concluded that peptides are currently much more successful as therapeutics than small molecules. In addition to proteins and peptides, five amino acids, four natural products, one steroid and one nucleoside have emerged. These data confirm that nature continues to be both the main source and the best inspiration for the drug-discovery process [5]. Several analysts have argued that the trend of a reduced number of new drugs entering the market during the mid-late 1990s may be linked to the diminishing interest in natural products at the beginning of the 1980 s in favor of computational methods as the driving technology for drug discovery [6]. It was widely propagated that computational methods significantly minimize time and resource requirements of chemical synthesis and biological tests, thereby reducing the cost of preclinical and clinical studies [7-9]. This field of study has matured over the last decade and it is now widely recognized that an integrated experimental and theoretical approach is required. Successful collaboration between scientists of various disciplines is required to accelerate the development of novel and effective products in the drug-discovery process [10].

TABLE I shows peptides approved by the FDA during the period 2009-2011 listed by the generic name, trade name, target disease and properties.

From a chemical view point, these peptides exemplify a broad range of structures, thereby showing that size and complexity do not jeopardize their arrival to the market (Figure 2). For example, the 60 -amino acid peptide ecallantide and the linear 31-amino acid sequence, liraglutide (a branched peptide with a palmitoyl-Glu moiety acylating through the $\gamma$-carboxylic acid the $\varepsilon$-amino of a Lys residue), are both large peptides; telavancin is a lipoglycopeptide, which is a synthetic derivative of vancomycin; romidepsin is a natural bicyclic depsipeptide, which contains a $\alpha, \beta$-didehydroamino acid and a disulfide bridge; boceprevir and telaprevir are small peptides that do not contain a single natural amino acid; and icatibant is a 10 -amino acid peptide that combines both natural and non-natural amino acids. An interesting case is brentuximab vedotin, which is an antibody-drug conjugate formed by the chimeric monoclonal antibody brentuximab linked through a dipeptide (Val-Cit), which is released by cathepsin B, and a self-immolative $p$-aminobenzyloxycarbonyl spacer, to the antimitotic peptide agent monomethyl auristatin E. This is an $O, N$-methyl peptidomimetic.

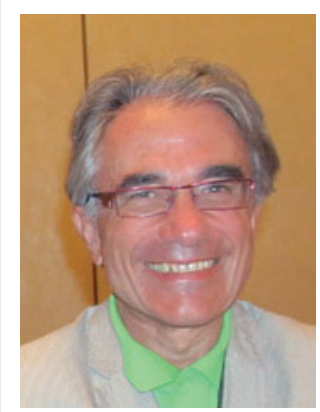

Fernando Albericio

Author for correspondence: Institute for Research in Biomedicine and

CIBER-BBN, Networking Centre on Bioengineering, Biomaterials \& Nanomedicine, Barcelona Science Park, 08028 Barcelona, Spain and

Department of Organic Chemistry, University of Barcelona, 08028 Barcelona, Spain and

School of Chemistry, University of KwaZulu-Natal, 404I Durban, South Africa

E-mail: fernando.albericio@ irbbarcelona.org

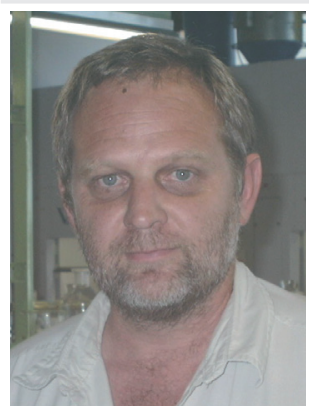

\section{Hendrik G Kruger}

School of Chemistry, University of KwaZulu-Natal, 404I Durban, South Africa 


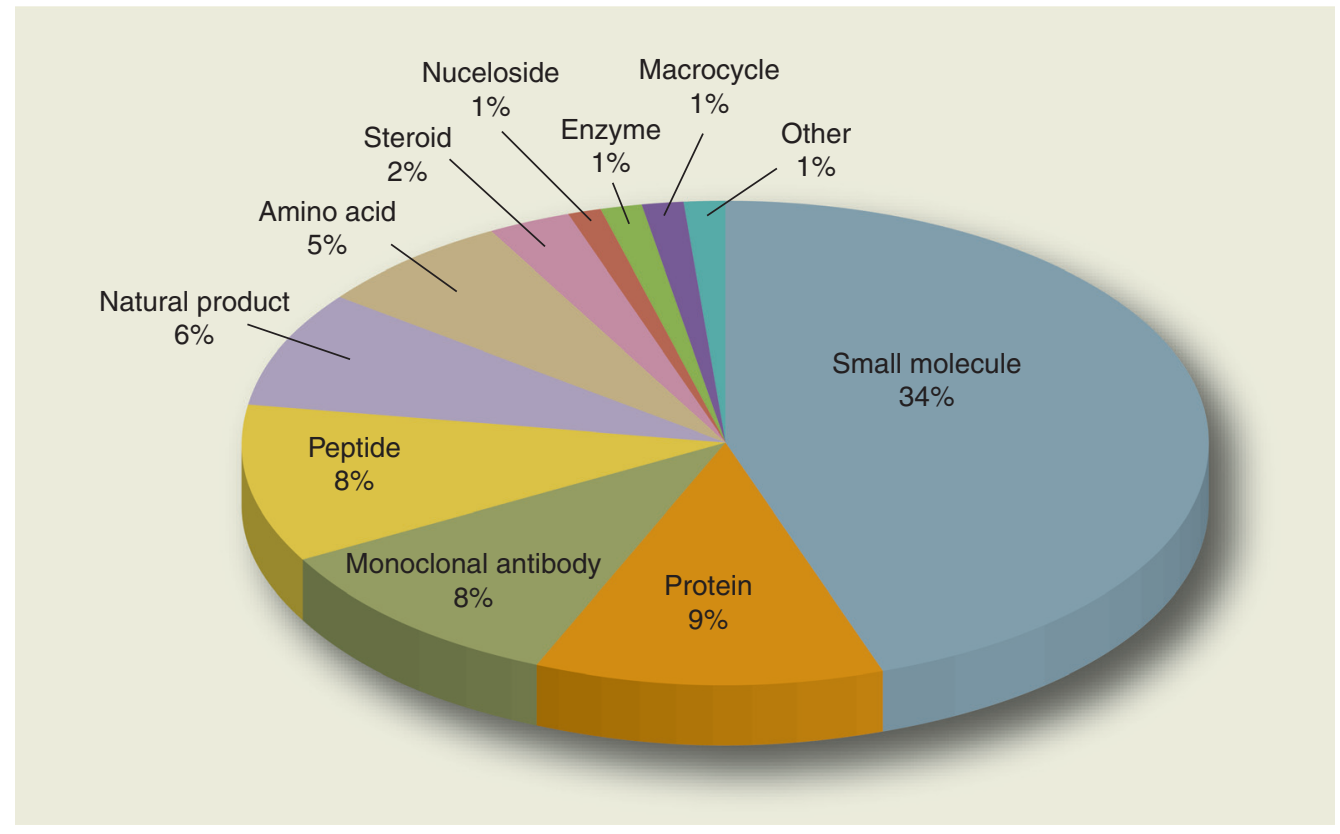

Figure 1. Distribution of the drugs approved by the US FDA by chemical species.

The analysis of these peptides by therapeutic categories is an indication of the versatility of peptides to tackle a large number of biochemical transgressions. Thus, boceprevir and telaprevir are antiviral therapeutics used for the treatment of hepatitis C; ecallantide and icatibant are cardiovascular agents; romidepsin and brentuximab vedotin are anticancer drugs; telavancin is an antibacterial; and liraglutide is used in metabolism for the treatment of Type 2 diabetes.

The expansion of the therapeutic applications of peptides is more visible when drugs in clinical and preclinical phases are analyzed. At present, in addition to almost 80 peptides on the market, approximately 200 more are in clinical phases and 400 in advanced preclinical stages [11,12]. Metabolism is currently the largest therapeutic field $(25 \%)$ for peptides, followed by cancer (16\%). This distribution marks an important change in trend, because towards the end of the previous century the use of peptides for the treatment of metabolic diseases was very limited. In addition, peptide drugs are demonstrating potential applications in other clinical fields, such as cardiovascular, CNS, gastrointestinal and autoimmune diseases [13].

Table 1. Peptides approved by the US FDA during the period 2009-2011.

\begin{tabular}{|c|c|c|}
\hline $\begin{array}{l}\text { Generic name } \\
\text { (trade name) }\end{array}$ & Disease/target & Properties \\
\hline $\begin{array}{l}\text { Ecallantide } \\
\left.\text { (Kalbitor }^{\circledR}\right)\end{array}$ & Hereditary angioedema & Plasma kallikrein inhibitor \\
\hline $\begin{array}{l}\text { Telavancin } \\
\left.\text { (Vibativ }^{\circledR}\right)\end{array}$ & Skin infection & Antibacterial agent \\
\hline $\begin{array}{l}\text { Romidepsin } \\
\left(\text { Istodax }{ }^{\circledR}\right)\end{array}$ & Cutaneous T-cell lymphoma & HDAC inhibitor \\
\hline $\begin{array}{l}\text { Liraglutide } \\
\left.\text { (Victoza }^{\circledR}\right)\end{array}$ & Type 2 diabetes & GLP-1 receptor agonist \\
\hline $\begin{array}{l}\text { Boceprevir } \\
\left.\text { (Victrelis }{ }^{\top M}\right)\end{array}$ & Hepatitis C Virus genotype 1 & NS3/4A protease inhibitor \\
\hline $\begin{array}{l}\text { Telaprevir } \\
\left(\text { Incivek }^{\circledR}\right)\end{array}$ & Hepatitis C Virus genotype 1 & NS3/4A protease inhibitor \\
\hline $\begin{array}{l}\text { Brentuximab vedotin } \\
\left.\text { (Adcetris }{ }^{\mathrm{TM}}\right)\end{array}$ & Hodgkin's lymphoma & CD30 directed \\
\hline $\begin{array}{l}\text { Icatibant } \\
\left(\text { Firazyr }^{\circledR}\right)\end{array}$ & Hereditary angioedema & Bradykinin B2 receptor antagonist \\
\hline
\end{tabular}


Glu-Ala-Met-His-Ser-Phe-Cys-Ala-Phe-Lys-Ala-Asp-Asp-Gly-Pro-Cys-Arg-Ala-Ala-His-Pro-Arg-Trp-Phe-Phe-Asn-Ile-Phe-Thr-ArgGln-Cys-Glu-Glu-Phe-Ile-Tyr-Gly-Gly-Cys-Glu-Gly-Asn-GIn-Asn-Arg-Phe-Glu-Ser-Leu-Glu-Glu-Cys-Lys-Lys-Met-Cys-Thr-Arg-Asp

\section{Ecallantide}

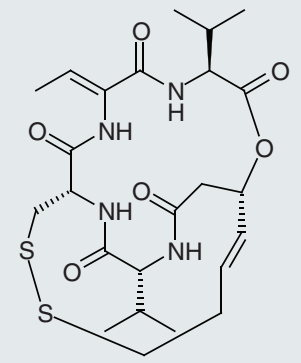

Romidepsin

H-His-Ala-Glu-Gly-Thr-Phe-Thr-Ser-Asp-Val-Ser<smiles>CC(C)(C)C(=O)C(C)(C)C</smiles>

Phe-Glu-Lys-Ala-Ala-Gln-Gly-Glu-Leu-Tyr-Ser<smiles>[In]C=[Te]</smiles>

Ile-Ala-Trp-Leu-Val-Arg-Gly-Arg-Gly-OH

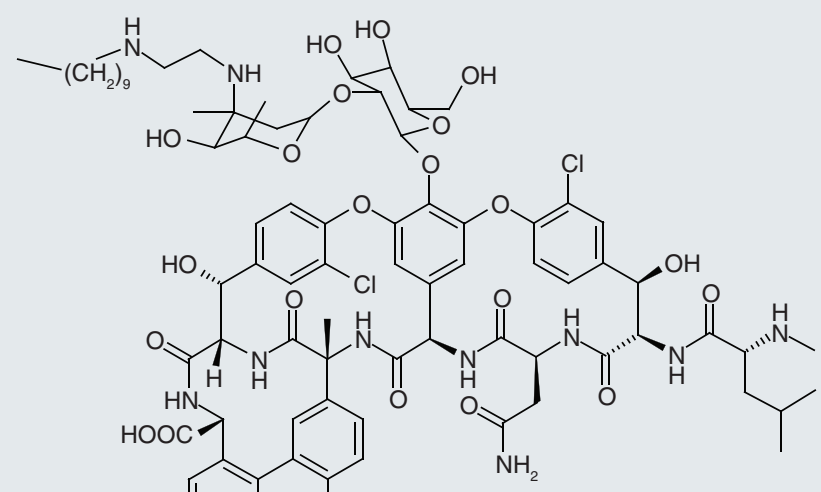

Telavancin

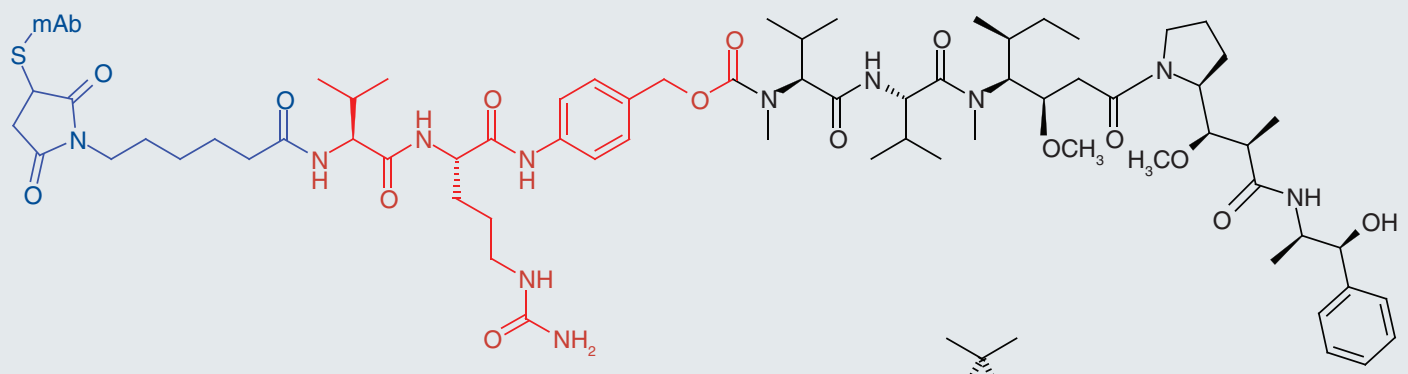

Brentuximab vedotin

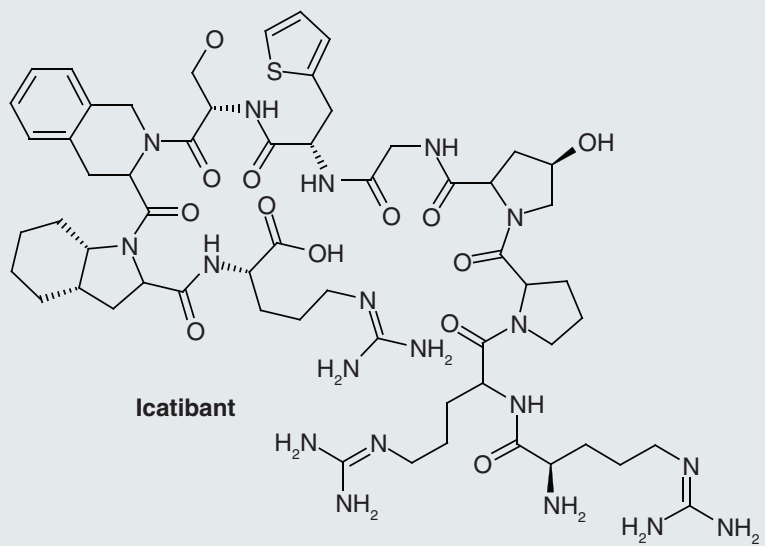<smiles>CC(C)(C)NC(=O)N[C@@H](C(=O)N[C@@H](CC1CCC1)C(N)=O)C(=O)C1CC2C(C1)C2C(C)(C)C</smiles>

Boceprevir<smiles>CCCC(NC(=O)[C@H]1[C@H]2CCC[C@@H]2CN1C(=O)[C@@H](NC(=O)[C@@H](NC(=O)c1cnccn1)C1CCCCC1)C(C)(C)C)C(=O)C(=O)NC</smiles>

Figure 2. Peptides approved by the US FDA during the period 2009-2011. In ecallantide, colors show the pairing of Cys; in Brentuximab vedotin, in black, the peptide monomethylauristatin $\mathrm{E}$, in red, the Val-Cit dipeptide, which is liberated by Cathepsin B, and a self-immolative $\mathrm{p}$-aminobenzyloxycarbonyl spacer; in blue, the monoclonal antibody modified. mAb: Monoclonal antibody. 
Peptides offer certain advantages as drugs; these include their high biological activity, high specificity and low toxicity. However, major obstacles preventing them from becoming active pharmaceutical ingredients are their lack of oral bioavailability and low stability under physiological conditions [14,15]. In light of this scenario, one can rightly ask why there has been a renaissance with respect to peptide drugs in the pharmaceutical industry. First of all, there has been a number of relatively large failures of some of the small-molecule-based drugs [16,17], which have been accompanied by substantial loss due to huge R\&D expenses. However, for peptides (thanks to robust peptide-chemistry strategies developed in recent years that take advantage of solid-phase methodologies as well as 'modern' solution organic synthetic chemistry), a much more optimistic picture emerges. These advances allow for more straightforward preparation of hit analogs, thereby favoring and speeding up the drug-discovery phases; namely hit discovery, hitto-lead and lead optimization. Thus, the choice of candidate and entrance to clinical phases are faster and more economical when compared with small molecules.

The paradigm of drug discovery is now being changed by the new tendency of pharmaceutical companies to directly develop a prodrug or a drug-delivery system. In the past, drugdelivery technologies were usually developed once the patent was close to expiry; examples of this new trend are the prodrug Brentuximab vedotin, which was accepted by the FDA in 2011; KAI-9803, which carries the cargo: a protein kinase $\mathrm{C}$ modulatory decapeptide; and a carrier, the TAT (47-57) peptide, linked by a disulfide bridge in one molecule. These exciting new drugs open the way for a large number of peptide therapeutics to enter the market in the near future. This new approach will also speed up research in both academia and industry, and thereby bring about a 'golden era' to the field of peptide research.
Given the growing importance of peptidebased drugs, this issue of Future Medicinal Chemistry is especially timely. The issue provides insights into the current trends in medicinal chemistry research relating to peptide therapeutics beginning with an interview with Loren Walenskey, who discusses issues relating to funding, his collaborative work and how stapled peptides could provide the next generation of therapy [18]. Almansour and colleagues report the potential use of the resonant recognition model and show their findings in a comparative study [19]. Dawgul et al. demonstrate the use of lipopeptides in the treatment of Staphylococcus aureus biofilm infections of the skin in their preliminary communication [20]. Biofilms are also the subject of the review by Jacobsen and Jenssen, discussing how recent research regarding the use of human cathelicidin LL-37 in human disease could lead to the development of analogues of the protein [21]. 'Intelligent peptides' are the focus of the article by Ahrens and co-workers; these next-generation peptide therapeutics have smart linkers that allow for a more target-oriented design as well as better blood plasma stability [22]. Recent innovations in cancer-targeting peptides relating to the benefits of cyclic and linear are discussed in the review by Roxin and Zheng [23]. Finally, the issue is completed with a discussion regarding how docking methods have become increasingly important in modern drug-discovery methods as Audie and Swanson describe in their article [24].

We hope you enjoy this special issue!

\section{Financial \& competing interests disclosure}

The authors have no relevant affiliations or financial involvement with any organization or entity with a financial interest in or financial conflict with the subject matter or materials discussed in the manuscript. This includes employment, consultancies, honoraria, stock ownership or options, expert testimony, grants or patents received or pending, or royalties.

No writing assistance was utilized in the production of this manuscript.

\section{References}

1 Joint Research Centre European Commission. The 2011 EU Industrial R\&D Investment Scoreboard. Publications Office of the EU, London, UK (2011).

2 Hughes B. 2009 FDA drug approvals. Nat. Rev. Drug Discov. 9(2), 89-91 (2010).

3 Mullard A. 2010 FDA drug approvals. Nat. Rev. Drug Discov. 10(2), 82-85 (2011).
4 Mullard A. 2011 FDA drug approvals. Nat. Rev. Drug Discov. 11(3), 91-94 (2012).

5 Newman DJ, Cragg GM. Natural products as sources of new drugs over the 30 years from 1981 to 2010 J. Nat. Prod. 75(3), 311-335 (2012).

6 Ganesan A. The impact of natural products upon modern drug discovery. Curr. Opin. Chem. Biol. 12, 306-317 (2008).
7 Sousa SF, Fernandes PA, Ramos MJ. Protein-ligand docking: current status and future challenges. Proteins 65, 15-26 (2006).

8 Marrone JT, Briggs MJ, Mccammon A. Structure-based drug design: computational advances. Annu. Rev. Pharmacol. Toxicol. 37, 71-90 (1997).

9 Sukumarand N, Das S. Current trends in virtual high throughput screening using 
ligand-based and structure-based methods. Comb. Chem. High Throughput Screen. 14, 872-888, (2011).

10 Caflisch A, Walchli R, Ehrhardt C. Computer-aided design of thrombin inhibitors. News Physiol. Sci. 13, 182-189 (1998).

11 Danho W, Swistok J, Khan W et al. Opportunities and challenges of developing peptide drug in the pharmaceutical industry. In: Peptides for Youth. The Proceedings of the 20th American Peptide Symposium. Del Valle S, Escher E, Lubell WD (Eds). Springer Science and Business Media, New York, NY, USA, 467-468 (2009).

12 Vlieghe P, Lisowski V, Martinez J, Khrestchatisky M. Synthetic therapeutic peptides: science and market. Drug Discov. Today 15(1/2), 40-56 (2010).

13 Ayoub M, Scheidegger D. Peptide drugs, overcoming the challenges, a growing business. Chem. Today 24, 46-48 (2006).

14 Bruckdorfer T, Marder O, Albericio F. From production of peptides in milligram amounts for research to multi-tons quantities for drugs of the future. Curr. Pharm. Biotech. 5, 29-43 (2004).

15 Zompra AZ, Galanis AS, Werbitzky O, Albericio F. Manufacturing peptides as active pharmaceutical ingredients. Future Med. Chem. 1(2), 361-377 (2009).

16 Pease JE, Horuk R. Small molecule antagonists of chemokine receptors - is promiscuity a virtue? Curr. Topics Med. Chem. 10(13), 1351-1358 (2010).

17 Meanwell NA. Improving drug candidates by design: a focus on physicochemical properties as a means of improving compound disposition and safety. Chem. Res. Toxicol. 24(9), 1420-1456 (2009).

18 Walensky LD. Interview with Loren D Walensky. Future Med. Chem. 4(12), 1537-1539 (2012).

19 Almansour NM, Pirogova E, Coloe PJ, Cosic I, Istivan TS. Investigation of cytotoxicity of negative control peptides versus bioactive peptides on skin cancer and normal cells: a comparative study. Future Med. Chem. 4(12), 1553-1565 (2012).
20 Dawgul M, Baranska-Rybak W, Kamysz E, Karafova A, Nowicki R, Kamysz W. Activity of short lipopeptides and conventional antimicrobials against planktonic cells and biofilms formed by clinical strains of Staphylococcus aureus. Future Med. Chem. 4(12), 1541-1551 (2012).

21 Jacobsen AS, Jenssen H. Human cathelicidin LL-37 prevents bacterial biofilm formation. Future Med. Chem. 4(12), 1587-1599 (2012).

22 Ahrens VM, Bellmann-Sickert K, BeckSickinger AG. Peptides and peptide conjugates: therapeutics on the upward path. Future Med. Chem. 4(12), 1567-1586 (2012).

23 Roxin Á, Zheng G. Flexible or fixed: a comparative review of linear and cyclic cancer-targeting peptides. Future Med. Chem. 4(12), 1601-1618 (2012).

24 Audie J, Swanson J. Recent work in the development and application of protein-peptide docking. Future Med. Chem. 4(12), 1619-1644 (2012). 